\title{
O IMPACTO DOS CONFLITOS NO CLIMA ORGANIZACIONAL DE UMA EMPRESA DO RAMO DO AGRONEGÓCIO ${ }^{1}$
}

\author{
THE IMPACT OF CONFLICTS ON THE ORGANIZATIONAL \\ CLIMATE OF AN AGRIBUSINESS BRANCH
}

\author{
Bibiana da Trindade Nogueira ${ }^{2}$, Patrinês Aparecida França Zonatto ${ }^{3}$, \\ Scheila Daiana Severo Hollveg ${ }^{4}$ L Lissandro Dorneles Dalla Nora ${ }^{5}$
}

\section{RESUMO}

O estudo do clima organizacional em uma empresa do ramo do agronegócio é uma importante ferramenta de gestão estratégica que possibilita a empresa identificar a percepção dos colaboradores em relação ao ambiente organizacional. Neste contexto, o trabalho contou com o objetivo geral de analisar de que forma os conflitos podem influenciar o clima organizacional em uma empresa do ramo do agronegócio. O estudo justifica-se, pois, grande parte das empresas desse ramo rural não possuem um adequado controle do seu clima organizacional e consequentemente não avaliam a satisfação de seus colaboradores. Esta pesquisa se caracteriza como um estudo de caso, onde foi utilizada uma abordagem descritiva e quantitativa dos dados. A coleta deu-se através da aplicação de um questionário aos colaboradores. Os resultados encontrados pela análise feita das respostas foi que os conflitos nem sempre se dão entre os colaboradores e sim com a gestão da empresa mais especificamente na falha de comunicação gestor/ funcionário e no ambiente de trabalho não satisfatório.

Palavras-chave: gestão estratégica, qualidade de vida, empresas.

\section{ABSTRACT}

The study of the organizational climate in an agribusiness company is an important strategic management tool that enables the company to identify the perception of employees in relation to the organizational environment. In this context, the work had the general objective of analyzing how conflicts can influence the organizational climate in an agribusiness company. The study is justified, therefore, most of the companies in this rural branch do not have an adequate control of their organizational climate and, consequently, do not evaluate the satisfaction of their collaborators. This research is characterized as a case study, where a descriptive and quantitative approach to the data was used. The collection took place through the application of a questionnaire to employees. The results found by the analysis made of the responses was that conflicts do not always occur between employees, but with the management of the company more specifically in the manager / employee communication failure and in the unsatisfactory work environment.

Keywords: strategic management, quality of life, companies.

1 Trabalho Final de Graduação.

2 Autora. Universidade Franciscana - UFN. E-mail: bibitn1997@gmail.com

3 Orientadora. Universidade Franciscana - UFN. E-mail: patrines.franca@ufn. edu.br

4 Autora. Universidade Franciscana - UFN. E-mail: scheilahollveg@hotmail.com

5 Autor. Universidade Franciscana - UFN. E-mail: lissandro@ufn. edu.br 


\section{INTRODUÇÃO}

No cenário contemporâneo torna-se essencial um estudo mais aprofundado sobre o comportamento organizacional e suas variáveis, já que as mudanças que afetam a maneira de pensar e agir dos colaboradores é inevitável nesse cenário atual conturbado e turbulento. Nesse contexto, pode-se dizer que as organizações também passam por constantes transformações, tanto na sua forma física quanto no modo de interagir com as pessoas e o ambiente no qual se encontram. Desse modo, o cenário interno e as mudanças que ocorrem na organização são as maiores causas dos conflitos que influenciam diretamente no clima organizacional.

De fato, os conflitos sempre existiram e sempre estarão presente em nossas vidas pessoais e profissionais, ou seja, faz parte do desenvolvimento humano, porém nos cabe ter autoconhecimento dos nossos conflitos internos, para assim podermos gerir os conflitos que estão em nosso meio. Conforme Robbins, Judge e Sobral (2010, p. 6), o comportamento organizacional é um campo de estudos que investiga o impacto que indivíduos, grupos e a estrutura organizacional tem sobre o comportamento das pessoas dentro das organizações, com o propósito de utilizar esses conhecimentos para melhorar a eficácia organizacional.

Entretanto, a necessidade de adaptação as mudanças não são exclusivamente dos gestores, mas sim de todos os membros que participam do processo organizacional, pois as mudanças impactam de forma relevante na gestão de pessoas, visto que o trabalho ocupa um papel central nas suas vidas, pois contribui para a formação de identidade e inclusão social, que por sua vez, pode gerar a qualidade de vida pautada diretamente no desempenho de cada indivíduo.

A qualidade de vida no ambiente da empresa está muito ligada as condições de trabalho e a satisfação dos colaboradores, seja pelas condições físicas, salários, políticas e diretrizes da empresa, o estilo de supervisão, entre outros. Existe uma relação entre trabalho e qualidade de vida, destacada quando existe relação direta entre ambas, refletindo para melhor ou pior a vida de cada colaborador. É descrito ainda que o trabalho associado ao prazer, será um elemento importante para gerar qualidade de vida (DYNIEWICZ, 2017).

Dessa forma, é importante que as empresas avaliem seu clima organizacional proporcionando a seus colaboradores, um ambiente de trabalho satisfatório possibilitando inclusive melhorias na produtividade e eficácia desde o nível estratégico até o operacional, onde surge então, a necessidade de compreender como os conflitos organizacionais afetam o clima organizacional?

Nesse sentido, o trabalho tem como objetivo geral analisar de que forma os conflitos podem influenciar o clima organizacional em uma empresa do ramo do agronegócio. Para atender o objetivo geral desta pesquisa, definiu-se os seguintes objetivos específicos: Verificar as condições de trabalho dos colaboradores que influenciam na qualidade de vida dos mesmos; identificar os tipos de conflitos mais constantes na organização; analisar fatores que podem ocasionar possíveis conflitos na organização. 
A importância de tal estudo reside que muitas organizações não levam em consideração os fatores do comportamento organizacional e acabam banalizando as questões de clima, restringindo assim as condições necessárias para a qualidade de vida e o desenvolvimento das atividades de suas equipes. Portanto a reflexão acerca do comportamento organizacional e suas três variáveis é de extrema importância visto que afeta direta e indiretamente o ambiente de trabalho. De acordo com Vecchio (2008), a comunicação bem sucedida nem sempre é possível, o que contribui com a disseminação de que a má comunicação é responsável por inúmeros problemas nas organizações, gerando assim os conflitos. Ainda pode-se identificar que o que mais afeta o clima organizacional são os conflitos, pois, o olhar da atualidade sobre os conflitos busca compreendê-los, analisando a organização e seus dados de missão, valores e objetivos organizacionais para assim então começar as possíveis análise das diferentes causas de conflito, buscando atrelar os fatores internos e os externos (AGOSTINI, 2005).

Essa realidade dos possíveis conflitos organizacionais decorre de diversos fatores como a oposição de ideais e pensamentos dentro do grupo, mas a partir disso é competência de o gestor contornar essas situações desagradáveis com soluções inteligentes e construtivas. Conforme a pesquisa realizada por Carvalho, Peduzzi e Ayres (2014, p. 4), "Constata-se que a posição que os diferentes trabalhadores ocupam no processo de trabalho, mais nuclear ou periférica, faz com que vivenciem o ambiente de trabalho e as tensões presentes nesse espaço de maneira distinta, contribuindo para a existência de concepções também distintas sobre o conflito".

Conforme Barbosa (2015), foi constatado que os conflitos mais comuns são os entre colegas de trabalho por apresentarem diferenças de personalidade, ideias, costumes e pensamentos que colidem entre si e que geralmente, afetam o desempenho de toda a equipe, devido ao seu poder negativo. Não existe uma receita única para resolvê-los, mas cabe ao gestor gerenciar os conflitos, extraindo o que for de positivo da situação.

Geralmente o clima organizacional é mutável dentro da organização, visto que, ele é afetado pela cultura organizacional, que normalmente interfere na qualidade de vida dos colaboradores. Com o objetivo de atrair atenção para o tema, o trabalho apontará os possíveis motivos pelos quais os conflitos organizacionais afetam a qualidade de vida no trabalho mais especificamente a saúde mental e psíquica, e como as variáveis da cultura organizacional influenciam no trabalho e afetam o desempenho dos colaboradores. Dessa forma, o presente estudo tem o foco nestas variáveis buscando melhorar o clima organizacional dentro do ambiente de trabalho, pois ao melhorar o clima organizacional haverá não apenas contribuições aos funcionários e sim para a sociedade local, com um clima mais agradável estes terão mais motivação e disposição no dia a dia, consequentemente terão mais disposição nos atendimentos gerando uma melhor impressão da organização. 


\section{CLIMA ORGANIZACIONAL}

Oliveira, Carvalho e Rosa (2012), relatam que o clima organizacional faz parte de todo o ambiente da empresa, incluindo subordinados, supervisores e direção. O relacionamento entre as pessoas do trabalho deve ser saudável para que a empresa também esteja com saúde, este assunto está ligado diretamente com a satisfação do trabalhador e seus resultados na corporação. Dessa forma, então, o clima está atrelado ao grau de satisfação do pessoal com o ambiente interno da empresa o que se vincula com a motivação, a lealdade e a identificação, tornando assim um ambiente mais favorável e agradável de trabalho (LACOMBE, 2005).

De acordo com Luz (2003, p. 25), "Há duas formas de avaliação do clima, e há dois níveis de responsabilidade na sua avaliação": Avaliação setorial - Ouvir individualmente os membros de sua equipe de trabalho é responsabilidade de cada gestor; Avaliação corporativa ou institucional - Avaliar o clima da organização é responsabilidade do RH e compete a ele ouvir coletivamente os funcionários.

Dentre os fatores que influenciam o clima, o comportamento, as atitudes e as decisões dos funcionários de forma direta ou indireta são os fatores internos e externos, sendo que, os fatores internos são os que se originam dentro da própria empresa, e que podem atuar diretamente sobre esses fatores para tentar melhorá-los e produzir melhores resultados para a empresa, os clientes e os funcionários, já os fatores externos são os que têm origem fora da empresa, mas que influenciam diretamente no comportamento, ações e decisões dos funcionários dentro da empresa, por isso sua importância (BISPO, 2006).

O que afeta o clima organizacional são os conflitos, sejam por situações positivas ou situações negativas que ocorrem no ambiente de trabalho e também por fatores externos, sendo que os acontecimentos internos são aqueles que mais impactam o clima (FERREIRA, 2013). De acordo com Ferreira (2013, p. 47), "a pesquisa de clima é uma importante ferramenta de gestão estratégica, pois possibilita a empresa identificar como os colaboradores sentem e percebem o clima organizacional". A pesquisa de clima organizacional, que é a base para geração dos diversos indicadores, tem normalmente o propósito de identificar a percepção dos empregados com relação a organização, permitir o entendimento dos pontos com potencial de melhoria entre o que a organização pretende ser e a maneira como está sendo percebida e por fim estimular o alinhamento de expectativas da organização e dos empregados (ASSIS, 2014).

Conforme Luz (2003), não podemos confundir uma estratégia de avaliação de clima com um indicador de clima organizacional. A avaliação é utilizada pela empresa para conhecer, detalhadamente, o seu clima, enquanto que um indicador serve apenas como um indicio, um sinal, um alerta sobre o clima. Apesar de se tratar de algo abstrato, é possível mensurar o clima organizacional através de indicadores que medem seu impacto na qualidade dos serviços prestados e permitem verificar se algo não está dentro da situação esperada pela empresa. O quadro 01 apresenta indicadores de mensuração do clima organizacional: 
Quadro 01 - Indicadores do clima organizacional.

\begin{tabular}{|l|l|}
\hline \multicolumn{1}{|c|}{ Indicadores } & \multicolumn{1}{c|}{ Descrição } \\
\hline Rotatividade de pessoal & Pode indicar falta de comprometimento das pessoas com a empresa \\
\hline Absenteísmo & Excessivo número de faltas e atrasos, falta de comprometimento com a empresa \\
\hline Pichações nos banheiros & $\begin{array}{l}\text { Onde estão as críticas e agressões direcionadas aos líderes, indicando a } \\
\text { insatisfação }\end{array}$ \\
\hline Programas de sugestões & $\begin{array}{l}\text { Falta de comprometimento do colaborador que não reage a empresa como } \\
\text { o esperado }\end{array}$ \\
\hline Avaliação de desempenho & Quando o desempenho está ruim pode indicar que o clima também está ruim \\
\hline Greves & Revela o descontentamento com a empresa \\
\hline Conflitos interpessoais e interdepartamentais & $\begin{array}{l}\text { Se houver muitos conflitos entre os departamentos e os colaboradores a } \\
\text { empresa deve ter mais atenção }\end{array}$ \\
\hline Desperdícios de materiais & $\begin{array}{l}\text { Uma forma que os funcionários usam para mostrar sua insatisfação para a } \\
\text { empresa é desperdiçando materiais, quebrando equipamentos. }\end{array}$ \\
\hline
\end{tabular}

Fonte: Adaptado de Luz (2003).

Conforme Luz (2003), nos conceitos dos diferentes autores, sobre clima organizacional, podemos encontrar pelo menos três palavras chave, que estão quase sempre presentes: Satisfação (dos funcionários) Os conceitos nos remetem a relação do clima com o grau de satisfação das pessoas que trabalham em uma organização; Percepção (dos funcionários) Se os funcionários percebem a empresa positivamente, o clima tende a ser bom, ao contrário, se eles percebem mal a empresa, o clima tende a ser ruim; Cultura (organizacional) O clima e a cultura normalmente costumam ser comparados, isso porque a cultura influencia o clima.

\section{COMPORTAMENTO E CULTURA ORGANIZACIONAL}

De acordo com Siqueira (2002), as primeiras tentativas de delimitar o comportamento organizacional surgiram na década de 60, quando Pugh definiu-o como o estudo da estrutura e do funcionamento de organizações e do comportamento de grupos e indivíduos dentro delas, defendendo a ideia de tratar-se de uma ciência emergente e quase independente, apoiada em outras disciplinas como Psicologia, Sociologia e Economia. Ainda para Robbins (2005) a essência da cultura organizacional é composta por sete características: inovação e assunção de riscos; atenção aos detalhes; orientação para resultados; orientação para pessoas; orientação para equipe; agressividade e estabilidade.

A cultura das organizações pode ser transmitida aos colaboradores de diversas formas, por meio de documentos escritos, por meio de reuniões, seminários e palestras. No entanto a forma mais forte de ensinar a cultura é por meio das ações e decisões administrativas que são vivenciadas dentro das organizações, nas quais estão ligadas ao comportamento organizacional, influenciando, dessa forma, no clima (LACOMBE, 2005).

Toda organização possui uma cultura própria que a identifica e que forma o conjunto dos seus costumes, suas crenças e seus valores. É pela sua cultura que uma empresa fixa a marca do seu 
perfil e também orienta ou controla o comportamento daqueles que a compõem (MARRAS, 2016). Dessa forma, a cultura organizacional pode ser definida como os valores e normas compartilhados que existem em uma organização e são transmitidos aos colaboradores por meio das crenças e sentimentos comuns, comportamentos regulares e um processo histórico para transmissão desses valores (VECCHIO, 2008).

Para Robbins (2005) a cultura organizacional se refere a maneira pela qual os funcionários percebem as características da cultura da empresa, e não ao fato de eles gostarem ou não delas. Trata-se de um conceito descritivo que diferencia do conceito da satisfação com o trabalho. De acordo com Vecchio (2008), ainda que o conhecimento sobre cultura organizacional seja um pouco limitado para indicar normas detalhadas para criação e preservação de cultura organizacional, existem pelo menos quatro influencias sobre as origens da cultura organizacional, que são as crenças e os valores do fundador de uma organização, as normas adotadas pela sociedade do país nativo ou no qual a empresa opera, problemas de adaptação externa e sobrevivência e problemas de integração interna.

Em uma cultura organizacional forte o impacto sobre o comportamento dos funcionários é maior e estão mais diretamente relacionados a redução da rotatividade, os valores essenciais da organização são intensamente acatados e compartilhados (ROBBINS, 2005). Para Schein (1992) apud Crozatti (1998, p. 12), a cultura de uma organização pode ser definida como um conjunto de pressuposições básicas compartilhadas que o grupo de pessoas nela envolvido aprendeu como resolvem seus problemas de adaptação externa e integração interna, que tem funcionado suficientemente bem para ser considerada válida e, da mesma forma, assimilada pelos novos membros como a maneira correta de perceber, pensar e sentir em relação aos problemas. A cultura pode ser transmitida aos funcionários de diversas maneiras, e as mais poderosas são as histórias, os rituais, os símbolos e a linguagem” (ROBBINS, 2005, p. 385). Para Robbins (2005), as histórias se referem a eventos ocorridos com fundadores de empresas, quebras de regras, sucessos estrondosos, redução de força de trabalho, recolocações de funcionários, reações a antigos erros, lutas organizacionais. Essas práticas vinculam o presente com o passado e oferecem explicação e legitimidade para o ocorrido na atualidade.

Os rituais são caracterizados por sequencias repetitivas de atividades que reforçam os valores da organização, os objetivos mais importantes e quais as pessoas são indispensáveis e quais são dispensáveis (ROBBINS, 2005). De acordo com Robbins (2005), os símbolos representam aos funcionários quem é importante, qual o grau de igualdade almejado pelos dirigentes e o tipo de comportamento considerado apropriado, já outros, poderiam incluir a elegância do mobiliário e a aparência e vestuário dos executivos.

Muitas organizações e unidades dentro de organizações utilizam a linguagem como forma de identificação dos membros de sua cultura ou subcultura. "Ao aprender essa linguagem, os membros demonstram sua aceitação da cultura e, assim fazendo, ajudam a preserva-la” (ROBBINS, 2005, p. 386). 
A cultura da empresa é considerada um recurso da administração que serve para definir a forma como as estratégias são executadas e a natureza da conduta com os diferentes públicos, e tem finalidade de alcançar os objetivos da mesma forma que a tecnologia, os insumos de produção, os equipamentos, os recursos financeiros e os recursos humanos (LACOMBE, 2005). Ainda para Lacombe (2005), a cultura se manifesta de muitas formas, vale lembrar que não existem valores independentes de recompensas, de forma que um desvio significativo na forma como as coisas devem ser feitas requer um redirecionamento para a cultura da organização.

\section{QUALIDADE DE VIDA NO TRABALHO}

A qualidade de vida nas organizações é muito importante para as pessoas que fazem parte dela. Do ponto de vista das pessoas, pode-se dizer que qualidade de vida é a percepção de bem-estar, a partir das necessidades individuais, ambiente social e econômico e expectativa de vida (FRANÇA). França (2014), descreve os níveis de atuação de qualidade de vida que são a gestão estratégica que ocorre quando declarada na missão e política da empresa, juntamente com a imagem corporativa, já a gestão gerencial é voltada para a atribuição dos líderes e chefes das áreas e departamentos com ênfase em objetivos, metas e produtividade organizacional e a gestão operacional que visa o bem-estar e a conscientização de novas práticas de estilo de vida para as pessoas da empresa. De acordo com Junior, Hunt e Osborn (1999), o termo qualidade de vida no trabalho expressa uma forma especial de pensar a respeito das pessoas, do seu trabalho e das organizações nas quais suas carreiras são realizadas.

Modelos de QVT Chiavenato (1999), descreve que para Nadler e Lawler, a QVT está fundamentada em quatro aspectos: a participação dos funcionários nas decisões; reestruturação do trabalho através do enriquecimento das tarefas e de grupos autônomos de trabalho; inovação no sistema de recompensas para influenciar o clima organizacional e melhoria no ambiente de trabalho quanto às condições físicas e psicológicas, horário de trabalho etc.

Modelo de Hackman e Oldhan conforme Chiavenato (1999), as dimensões do cargo são fundamentais na QVT, estes aspectos produzem estados psicológicos críticos que conduzem a resultados pessoais e de trabalho que afetam diretamente a qualidade de vida no trabalho, que são: Variedades de habilidades: o cargo exercido deve exigir várias e diferentes habilidades e conhecimento; Identidade da tarefa: ressalta a importância do indivíduo sobre as suas tarefas, o trabalho deve ser realizado do início ao fim, para que este perceba que produz um resultado palpável; Significado da tarefa: a pessoa deve ter uma clara percepção de que forma o seu trabalho produz consequência e impactos sobre o trabalho dos demais; Autonomia: defende-se a responsabilidade pessoal para planejar e executar as tarefas e independência para desempenhá-las. A meta principal do programa de QVT é a conciliação dos interesses dos indivíduos e das organizações, ou seja, ao melhorar a satisfação do trabalhador, melhora-se a produtividade da empresa (CONTE, 2003). 


\section{CONFLITOS ORGANIZACIONAIS}

Conforme Nascimento e El Sayed (2002), conflitos organizacionais existem desde o início da humanidade, fazem parte do processo de evolução dos seres humanos e são necessários para o desenvolvimento e o crescimento de qualquer sistema organizacional. "Conflito pode ser um problema sério em uma organização. Ele é capaz de gerar condições caóticas que tornam praticamente impossível que os funcionários trabalhem em conjunto" (ROBBINS, 2005, p. 326).

Ainda de acordo com Robbins (2005), a definição de conflitos se dá por meio de um processo que tem início quando uma das partes percebe que a outra parte afeta, ou pode afetar, negativamente alguma coisa que a primeira considera importante. Para Almeri, Barbosa e Nascimento (2015), a junção de pessoas com diferentes personalidades, interesses, valores, estilos, etnia e idade, podem gerar os chamados conflitos interpessoais que são também identificados por serem conflitos disfuncionais que acarretam hostilidade entre os envolvidos, muitas vezes gerando no ambiente organizacional atitudes negativas que são acompanhadas de raiva e ódio. Se levadas ao extremo podem resultar em caos e desordem, podendo levar a organização a falência, acontecimentos esses que são cada vez mais comuns dentro das organizações.

O conflito pode surgir de diversas fontes, agrupadas em três categorias gerais: fatores de comunicação, estruturais e de comportamento pessoal, o fator de comunicação quando má executado é atribuído a uma alta porcentagem dos conflitos, a comunicação verdadeira cria uma imagem ao receptor com exatamente os mesmos detalhes pretendidos pelo emissor, nos fatores estruturais indicam que os maiores conflitos existem nas organizações de grande porte, e também está ligada as diferenças entre os colaboradores, em termos de autoridade, idade e valores, já nos fatores do comportamento pessoal, existem pessoas predispostas ao conflito, indivíduos imensamente autoritários (VECCHIO, 2008).

Conforme Robbins (2005), os conflitos geralmente são partes de um processo que é formado por cinco estágios: Estágio I: oposição potencial ou incompatibilidade, é o primeiro passo do processo do conflito, ou seja, são as condições necessárias para o seu surgimento, que estão agrupadas em três categorias (comunicação, estrutura e variáveis pessoais); Estágio II: cognição e personalização, é onde os envolvidos decidem sobre o que é conflito e as consequências que eles podem acarretar. Estágio III: intensões, ficam entre as percepções e emoções e o comportamento explicito das pessoas. Elas são decisões de agir de uma determinada maneira; Estágio IV: comportamento, é onde os conflitos se tornam visíveis, pois inclui as declarações, as ações e as reações das partes envolvidas no conflito. Estágio V: consequências, são basicamente as ações e reações de um conflito, que podem ser consequências funcionais, quando resultam em melhorias do desempenho do grupo, ou disfuncionais, quando atrapalham o seu desempenho.

Conforme Robbins, Judge e Sobral (2010), as possíveis visões de resolução de conflitos é formada pela visão tradicional e a visão interacionista: Visão tradicional de conflito, crença de que todo conflito é disfuncional e deve ser evitado a todo custo; Visão interacionista de conflito, crença de 
que o conflito é não apenas uma força positiva em grupo, mas absolutamente necessário para que seu desempenho seja eficaz. De acordo com Robbins (2005) uma das formas de resolução dos conflitos organizacionais é a negociação ou barganha, onde será dado ênfase a duas estratégias de barganha, a distributiva e a integrativa. Já a barganha integrativa ao contrário da distributiva, a resolução de problemas de maneira integrativa opera sob a premissa de que há um ou mais acordos que podem gerar uma solução ganha-ganha (ROBBINS, 2005).

Robbins, Judge e Sobral (2010), relatam que cruzando o grau de assertividade com o grau de cooperação é possível identificar as cinco estratégias de resolução de conflitos que são: Competição: estratégia focada na satisfação dos próprios interesses, independentemente do impacto que isso terá sobre as outras partes em conflito; Colaboração: quando ambas as partes desejam resolver os conflitos satisfazendo os interesses, dessa forma alcançando a satisfação mutua, sendo assim, colaborar significa que ambas as partes desejam esclarecer e solucionar os problemas; Evitamento: quando uma pessoa reconhece que o conflito existe, mas, em vez de procurar resolve-lo, busca supri-lo ou ignora-lo, ela está evitando o conflito; Acomodação é quando uma das partes sacrifica seus interesses ou aceita a opinião de alguém mesmo sem concordar totalmente só para manter uma boa relação; Compromisso: estratégia na qual as partes estão dispostas a abrir mão de alguma coisa para solucionar um conflito. Alméri e Barbosa (2015), relatam que os conflitos estão presentes em todas as organizações e que a maioria das pessoas tem ou tiveram um conflito no ambiente de trabalho e a parcela que não teve já presenciou conflitos entre os colegas isso acontece com maior frequência de envolvidos em um mesmo setor, mas cabe ao gestor gerencia-los da melhor forma possível.

\section{METODOLOGIA}

O trabalho desenvolvido tem por objetivo analisar como os conflitos organizacionais podem influenciar o clima organizacional de uma empresa no ramo do agronegócio. Para a realização deste estudo, foram considerados alguns critérios de avaliação e classificação, os quais serão descritos a seguir. Quanto aos objetivos a pesquisa classifica-se como descritiva. As pesquisas deste tipo, possuem a diretriz principal, a descrição das características de determinada população ou fenômeno ou o estabelecimento de relações entre variáveis (GIL,1994).

A pesquisa de natureza quantitativa tem suas raízes no pensamento positivista lógico, e enfatiza o raciocínio dedutivo, as regras da lógica e os atributos mensuráveis da experiência humana (GERHARDT, 2009). A pesquisa Quantitativa, por ser possível quantificar e cruzar as informações de modo objetivo utilizando a estatística (MICHEL, 2009). Quanto ao procedimento técnico foi realizado um estudo de caso que investiga um fenômeno contemporâneo e evidencia a coleta de dados ajudando a tratar a condição técnica distintiva, podendo incluir casos múltiplos ou únicos (YIN, 2015). Nesta pesquisa foi estudado uma única empresa. 
$\mathrm{O}$ instrumento utilizado para a coleta de dados foi o questionário. De acordo com Günther (2003), o questionário pode ser definido como um conjunto de perguntas sobre um determinado assunto ou algo que se deseja investigar, que não testa a habilidade do respondente, mas mede sua opinião, seus interesses e aspectos de personalidade.

O questionário utilizado na pesquisa foi desenvolvido pelos autores Luz (2006) e Carvalho (2011), aplicado aos dezoito colaboradores, com foco em avaliar o clima organizacional, através da opinião dos colaboradores da empresa pesquisada. Os principais fatores que foram analisados: perfil do empreendedor, ambiente de trabalho, reconhecimento pelo trabalho, identificação com a empresa, comunicação, conflito, remuneração e estabilidade. O questionário foi formatado de maneira simples e objetiva, levando em consideração que seus respondentes, que em geral não possuem o ensino médio completo. O mesmo foi composto por 18 perguntas de múltipla-escolha em escala Likert de 5 pontos, onde 1 corresponde discordo totalmente, 2 discordo parcialmente, 3 nem concordo, nem discordo, 4 concordo parcialmente e 5 concordo totalmente, a fim de conhecer o perfil dos contribuintes da empresa e identificar as possíveis causas dos conflitos. Após a coleta, os mesmos foram tabulados no Excel, gerando gráficos e posteriormente sendo analisados de maneira individual.

\section{ANÁLISE DOS RESULTADOS}

Neste capítulo estão detalhados os principais resultados alcançados mediante a aplicação do instrumento de coleta de dados, e a apuração da análise a fim de analisar de como os conflitos influenciam no clima organizacional da empresa em estudo. A propriedade está localizada no interior do município de São Martinho da Serra/RS. As principais atividades desenvolvidas são a agricultura (soja, milho e trigo) e a pecuária.

Através do levantamento realizado, identificou-se como os conflitos influenciam diretamente o clima organizacional na empresa pesquisada, no qual encontra-se de maneira detalhada os dados coletados. De acordo com a pesquisa realizada, quanto a idade dos colaboradores 3,17\% (3) possuem até 25 anos, 7,39\% (7) entre 25 a 35 anos, 7,39\% (7) entre 35 a 45 anos e 1,5\% (1) entre 45 a 55 anos, assim pode-se observar que a empresa possui uma variação de idades entre seus colaboradores que vai de pessoas jovens até pessoas mais velhas sendo a maior parte de seus colaboradores.

Em relação a escolaridade dos mesmos também se encontra uma variação significativa, onde 1,6\% (1) possuem ensino fundamental completo, 7,39\% (7) possuem ensino fundamental incompleto, $4,22 \%$ (4) possuem ensino médio completo, 4,22\% (4) possuem ensino médio incompleto e 2,11\% (2) ensino superior incompleto. Conforme a renda 9,50 (9) tem renda até 2 salários mínimos e 9,50 (9) entre 2 e 5 salários mínimos, 7,7\% (3) entre R\$ 3.500 e R\$ 4.500, 15,4\% (6) entre R\$ 4. 500 e R\$ 5.000, e 35,9 (14) mais que R \$ 5.000. Quanto ao tempo de empresa que cada colaborador possui pode observar-se que $12,67 \%$ (12) está até 5 anos, 4,22\% (4) entre 5 e 10 anos, 1,5\% (1) entre 10 e 15 anos 
e 1,6\% (1) entre 15 e 20 anos. Desta forma, observa-se que a empresa consegue desenvolver uma boa relação com seus colaboradores, devido ao tempo de serviço que cada um tem na empresa.

No gráfico 01, inicialmente buscou-se analisar a percepção dos colaboradores em relação as condições de trabalho na empresa em estudo. Observa-se no gráfico 1 que foi compilada as respostas de 6 questões referente as condições de trabalho.

Gráfico 01 - Percepção sobre condições de trabalho.

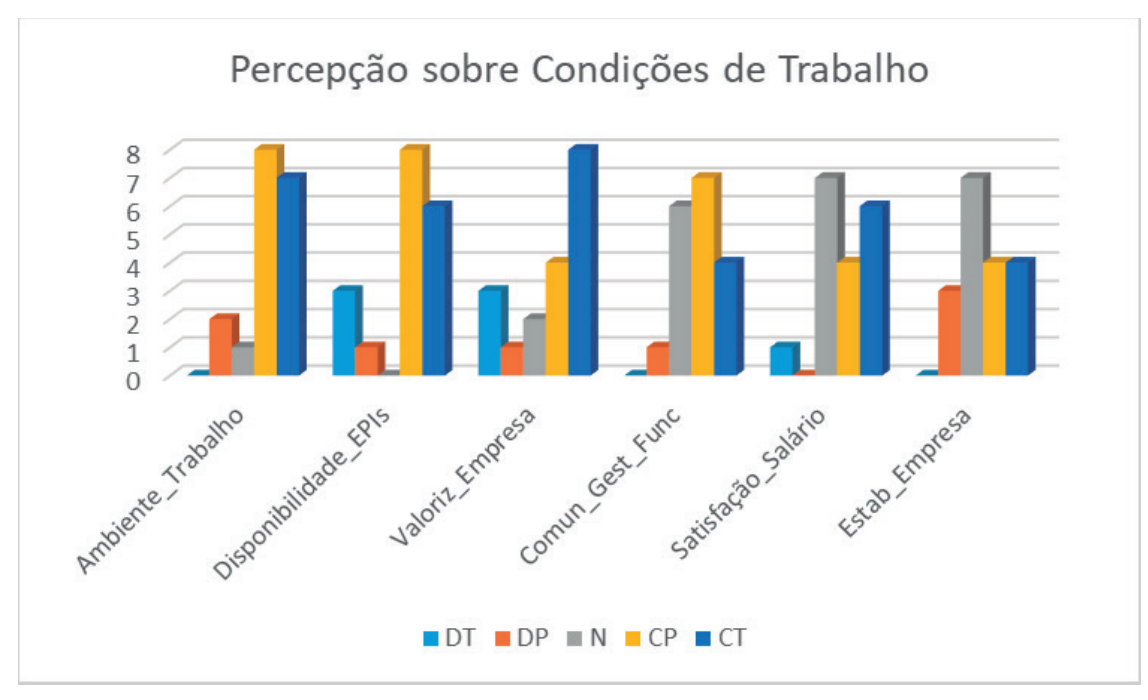

Fonte: dados da pesquisa

Como pode-se observar no gráfico 1, a primeira questão identificou-se o nível de satisfação dos colaboradores com o ambiente de trabalho da organização, o qual pode estar diretamente relacionado a produtividade dos mesmos. Onde $44,44 \%$ dos colaboradores não estão completamente satisfeitos com o ambiente de trabalho e 38,89\% estão satisfeitos com o ambiente onde trabalham, o que significa que a empresa de uma forma geral foi avaliada pelos colaboradores como um bom ambiente para se trabalhar. Quando se tem um ambiente agradável para exercer suas atividades, consequentemente aumenta a produtividade da empresa. Chiavenato (2008), relata que satisfação no ambiente de trabalho está ligada a dois fatores, os fatores higiênicos (fatores físicos e ambientais) e fatores motivacionais (fatores ligados ao cargo desempenhado).

A segunda questão também representada no gráfico 1, diz respeito da disponibilidade do Equipamento de Proteção Individual (EPI), onde a empresa entrega ao funcionário e faz o acompanhamento sobre a utilização do mesmo. O que faz com que o colaborador se sinta seguro e trabalhe com tranquilidade, realizando assim suas tarefas de forma eficaz, os colaboradores concordaram em partes em $44,44 \%$ que a empresa disponibiliza equipamentos de proteção e 33,33\% concordam totalmente com disponibilidade dos mesmos. Conforme citado por Lacombe (2005), a cultura da empresa é considerada um recurso da administração que serve para definir a forma como as estratégias são executadas e a natureza da conduta, que tem por finalidade de alcançar os objetivos da mesma forma que a tecnologia, os insumos de produção, os equipamentos, os recursos financeiros e os recursos humanos. 
O terceiro questionamento se refere a valorização do funcionário pela empresa, o ambiente de trabalho se deve muito aos gestores da empresa, os quais devem se preocupar com os colaboradores, tanto na sua vida pessoal quanto profissional para que os mesmos estando bem consigo possam produzir dentro da empresa de maneira efetiva. Como mostra o gráfico $44,44 \%$ dos funcionários se sentem valorizados pela empresa como deveriam, e 22,22\% concordam em partes quanto sua valorização pelos mesmos, enquanto $16,67 \%$ dos funcionários acreditam que não são valorizados pela empresa, o que demonstra que a empresa possui um número significativo de colaboradores insatisfeitos.

Esses resultados mostram que a empresa pode estar perdendo um grande número de produtividade, onde trabalhadores ao serem motivados, podem render de forma mais eficaz em prol da organização. De acordo com Lacombe (2005), um desvio significativo em como as coisas devem ser feitas requer um redirecionamento para a cultura da organização, onde o ambiente de trabalho tem que ser tratado de forma especial para que haja uma valorização de seu colaborador.

Na sequência buscou identificar como ocorre a comunicação entre os gestores e os funcionários. Nessa análise, é destacado que 38,89\% dos colaboradores afirmam que geralmente obtêm-se uma comunicação boa, 33,33\% se mostraram neutros em relação ao assunto e 22,22\% relatam ter uma ótima comunicação com os gestores, o que demonstra que a empresa possui uma boa comunicação com seus colaboradores a qual influência de forma positiva no clima organizacional. Ter uma boa comunicação ajuda na resolução de várias falhas na empresa, da mesma forma que ajuda a manter um clima agradável. Para Chiavenato (2008), a liderança é um fenômeno social e deve se utilizar da comunicação para definir objetivos específicos auxiliando um fluxo de informações corretas e significativas.

Após analisou-se a satisfação salarial do colaborador na empresa pesquisada. Deste modo, como mostra o gráfico 38,89\% dos colaboradores se mostraram neutros em relação ao assunto, 33,33\% se mostraram totalmente satisfeitos com seus salários e 22,22\% acham que seus salários poderiam ser melhores, o que pode ser um dos motivos dos conflitos no ambiente de trabalho, onde colaborador insatisfeito tende a não se esforçar ao máximo em suas atividades diárias. Desta forma, Siqueira (2002) explica o real valor recebido pelo trabalhador em relação a sua produtividade de trabalho, seu estilo de vida, sua capacidade de exercer tarefas e esforços para realizar as mesmas

$\mathrm{O}$ último questionamento demostrado no gráfico 1, refere-se à estabilidade na empresa, a qual interfere no planejamento de vida do colaborador, tanto no âmbito pessoal quanto profissional. No gráfico, é destacado que 38,89\% dos colaboradores se mostraram neutros e não opinaram sobre o assunto, 33,33\% afirmaram que possuem estabilidade e 33,33\% não se sentem totalmente seguros quanto a estabilidade. Conforme Robbins (2005), em uma cultura organizacional forte o impacto sobre o comportamento dos funcionários é maior e estão mais diretamente relacionados a redução da rotatividade, os valores essenciais da organização são intensamente acatados e compartilhados. No gráfico 02, apresenta a análise em relação a percepção dos colaboradores sobre as relações de trabalho. 
Gráfico 02 - Percepção sobre relações de trabalho

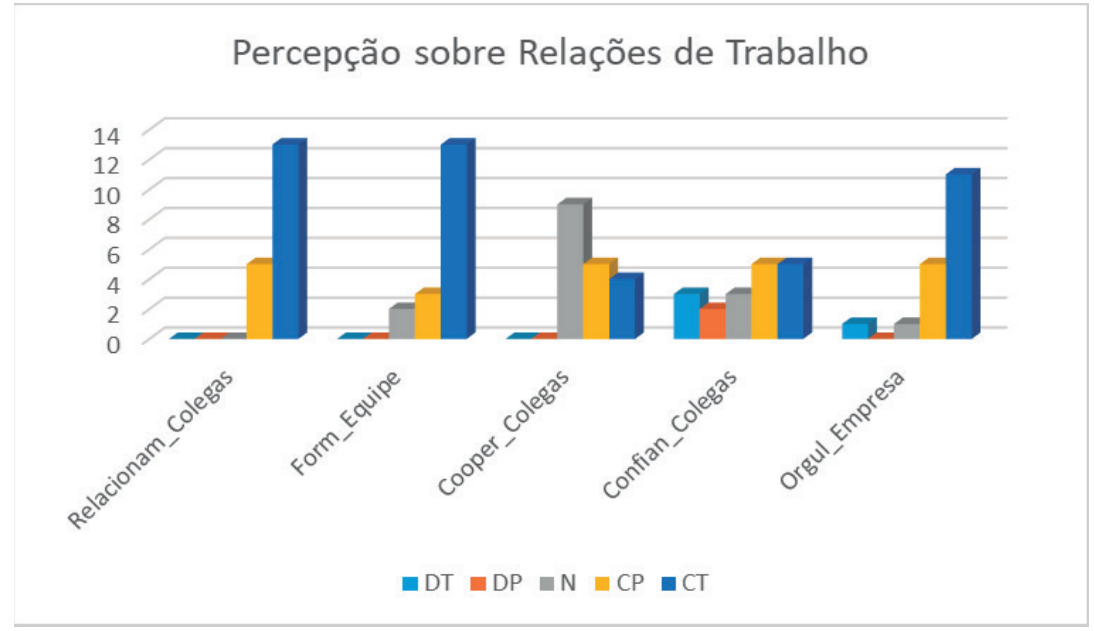

Fonte: dados da pesquisa

A primeira análise fala sobre a relação entre os colegas de trabalho, a relação está muito ligada a comunicação, onde há troca de informações corretas, existe boas relações interpessoais. O gráfico mostra que, $66,67 \%$ dos colaboradores afirmam que possuem boa relação com os colegas e $22,22 \%$ acreditam que a relação entre os colegas não é totalmente boa, a qual pode ser a causa de conflitos, se não existe boa comunicação entre os colaboradores, não existe entendimento e então surgem as desavenças. Conforme Bispo (2006), o comportamento, as atitudes, as decisões e as formas de se comunicar, são os fatores que influenciam no clima seja de forma direta ou indireta.

No questionamento seguinte buscou identificar se os colegas de trabalho formam equipe entre si, conforme também pode ser visualizado no gráfico 2, a maior parte dos colaboradores, $66,67 \%$ concordam que seu grupo de trabalho forma uma equipe, o que significa que, no que se trata de ambiente de trabalho os colaboradores estão dispostos a se ajudarem, assim obtendo um rendimento nas tarefas do setor. Dessa forma Lacombe (2005), traz que a satisfação e o engajamento do pessoal entre si estão atrelados ao ambiente interno da empresa, a motivação, a lealdade e um ambiente agradável de trabalho.

A análise que trata da cooperação dos colegas entre si, a maioria 44,44\% ficou neutro em relação ao assunto e $22,22 \%$ concordam em partes que exista cooperação, o que representa que nem sempre os colegas estão dispostos a se ajudarem. Conforme Carvalho, Peduzzi e Ayres (2014), a posição que os diferentes trabalhadores ocupam no processo de trabalho faz com que vivenciem as tensões existentes nesse espaço.

A próxima análise é sobre o nível de confiança entre os colegas de trabalho, o que representou respostas variadas em relação ao assunto o que talvez pode significar que nem todos os colegas são de confiança o que possivelmente pode ser o gerador dos conflitos, onde as duas respostas mais significativas foi $27,78 \%$ concordam parcialmente que existe confiança e $27,78 \%$ acreditam que podem confiar nos colegas de trabalho. Para Almeri, Barbosa e Nascimento (2015), a junção de pessoas com 
diferentes personalidades, interesses, valores, estilos, etnia e idade podem muitas vezes gerar conflitos ocasionando hostilidade entre os envolvidos e atitudes negativas no ambiente de trabalho.

A última análise se refere ao orgulho que os colaboradores sentem da empresa, onde $61,11 \%$ se sentem orgulhosos de trabalhar na empresa e $27,78 \%$ não sentem tanto orgulho. O que significa que a maioria dos colaboradores se sentem satisfeitos com a organização o que pode estar atrelado a cultura da empresa. Dessa forma, Marras (2016), traz que toda organização possui uma cultura própria e também orienta e controla o comportamento daqueles que a formam. Dando sequência as análises, no gráfico 03 está representado a percepção dos colaboradores em relação aos conflitos no trabalho. Alméri e Barbosa (2015), relatam que os conflitos estão presentes em todas as organizações e que a maioria das pessoas tem ou tiveram um conflito no ambiente de trabalho e a parcela que não teve já presenciou conflitos entre os colegas.

Gráfico 03 - Percepção sobre conflitos no trabalho

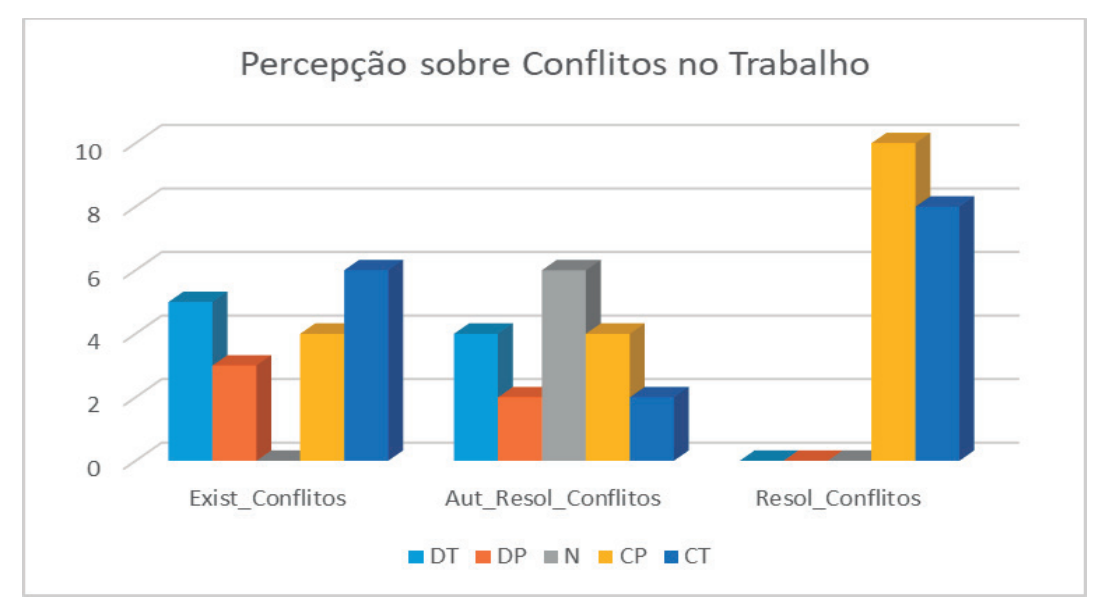

Fonte: dados da pesquisa

O primeiro questionamento se refere a existência de conflitos no local de trabalho não, onde as respostas mais significativas foram 33,33\% acham que não existem conflitos 33,33\% afirmam que existem conflitos, o que significa que nem todos os colaboradores estão satisfeitos com a relação entre os colegas o que impacta na qualidade de vida no ambiente de trabalho e no desenvolvimento das tarefas diárias. Conforme Conte (2003) o essencial para o desenvolvimento da QVT, seria conciliar os interesses dos indivíduos e da organização, dessa forma melhorando a satisfação do colaborador, o que geraria menos stress no trabalho e consequentemente menos conflitos e maior produtividade.

A próxima análise, trata se o colaborador tem autonomia para resolução de conflitos/melhorias na empresa, onde as respostas foram variáveis, mas a que apresentou valor mais significativo, 33,33\% dos colaboradores preferiram ficar neutros em relação ao assunto, não opinando sobre, o que pode ter ocasionado tal resposta é que talvez o dialogo dos colaboradores com os gestores seja falho. De acordo com Luz (2003) uma das formas de avaliar o clima é a avaliação corporativa ou institucional, onde fala 
que tal avaliação é de responsabilidade dos gestores e compete a ele ouvir individual ou coletivamente os funcionários.

A última análise avalia se os conflitos são resolvidos através do diálogo com os gestores e ou colegas de trabalho, onde maior parte dos colaboradores, 55,55\% acham que nem sempre os conflitos são resolvidos através do diálogo e 44,44\% acham que os conflitos se resolvem através do diálogo. O que se observa que maior parte dos funcionários acreditam que as pendências entre colaborador/ gestor não estão sendo resolvidas, o que acaba influenciando de forma negativa no clima da empresa e consequentemente afetando a produtividade. De acordo com Oliveira, Carvalho e Rosa (2012), relatam que o clima organizacional faz parte de todo o ambiente da empresa, incluindo subordinados, supervisores e direção, por isso a importância de se manter um ambiente saudável e sem conflitos na organização.

\section{CONCLUSÃO}

A importância da pesquisa de clima organizacional está muito atrelada em conhecer o comportamento de uma empresa em um dado momento, através da avaliação de variáveis que impactam positiva e negativamente no ambiente organizacional, permitindo mensurar o alcance das ações realizadas pela organização. Dessa forma, a presente pesquisa teve como objetivo geral analisar de que forma os conflitos podem influenciar o clima organizacional em uma empresa do ramo do agronegócio. Tendo como suporte para atender a pesquisa os objetivos específicos: Verificar as condições de trabalho dos colaboradores que influenciam na qualidade de vida dos mesmos; Identificar os tipos de conflitos mais constantes na organização; Analisar fatores que podem ocasionar possíveis conflitos na organização.

Para o alcance dos objetivos da presente pesquisa foi aplicado um questionário aos colaboradores da empresa em estudo direcionado ao tema, sendo abordado os seguintes fatores: ambiente de trabalho, reconhecimento, comunicação, conflito, remuneração e estabilidade. O qual foi possível identificar as condições de trabalho dos colaboradores a partir das respostas que estão presentes nos gráficos, onde as respostas mais significativas e que podem ser o motivo dos conflitos são em relação ao ambiente de trabalho, a disponibilidade de equipamentos de proteção, a satisfação com o salário, a estabilidade na empresa e a comunicação entre gestor/ funcionário.

Sendo que a relação entre os colaboradores foi verificada como boa, onde o que deixou a desejar foi quanto a confiança dos mesmos, o que deu a entender que os colegas têm um bom relacionamento, porém o nível de confiança um no outro demonstrou-se baixo, porém no ambiente de trabalho não necessariamente exista confiança, e sim comprometimento e profissionalismo e isso seria o suficiente para que as empresas tenham pessoas de boas ações trabalhando não para a satisfação individual, mas trabalhando para a produção em conjunto de valores e respeito. 
Dessa forma, o que justifica os possíveis conflitos na empresa pode estar mais atrelado a organização e as condições de trabalho do que a relação com os colegas de setor, conforme verificado na pesquisa. Dentre os fatores analisados ficou destacado positivamente o orgulho dos funcionários por estarem trabalhando na empresa, e a boa relação com os colegas de trabalho. Quanto aos conflitos existentes no ambiente de trabalho, o diálogo na solução dos problemas, a comunicação com os gestores e a valorização pela empresa, grande parte dessa insatisfação se deve pelo fato da empresa ser familiar e por ter familiares em diversas hierarquias da empresa, o que muitas vezes pode ser o gerador de falhas na comunicação, onde cada membro da família expõe seu ponto de vista o que afeta no entendimento por parte dos funcionários, dessa forma havendo informações precipitadas e desentendimentos.

Dessa forma como sugestões futuras a empresa, o que pode ser melhorado e priorizado é a preparação dos gestores em relação a liderança, sendo que as pessoas evoluem com o tempo adquirindo conhecimento e novas ambições, assim, para acompanhar a evolução, os gestores precisam estar se renovando e aprimorando em conhecimentos para extrair o melhor de cada funcionário, motivando os mesmo a vestirem a camisa da empresa. Onde funcionários motivados tendem a ter uma maior desenvoltura no ambiente de trabalho, consequentemente produzindo mais e mantendo um clima saudável.

Outra sugestão seria a empresa ter uma gestão de Relações Humanas (RH) estruturada, o que é fundamental, pois é um dos responsáveis por acompanhar as tendências do mercado, treinar e desenvolver pessoas, assegurar os direitos dos colaboradores e gerir o clima organizacional, assim garantindo que a equipe esteja motivada para entregar o melhor para a organização.

O ser humano é estimulado pelo ambiente que vive, dessa forma se ele se sentir feliz em seu ambiente organizacional, o qual reconhece seus esforços, estimula o crescimento profissional e proporciona recompensas, ele tende a entregar seu trabalho com maior qualidade. Então outra proposta para a organização em estudo seria investir no bem-estar do seu funcionário, entre os benefícios, estão, orientação nutricional, atividade física orientada, lanche no intervalo, sala de lazer com algum tipo de jogo, além de cursos de qualificação profissional, o que estimula o sentimento de pertencimento com a empresa, aumenta a produtividade a satisfação e potencializaria a entrega do colaborador.

\section{REFERÊNCIAS}

ALMÉRI, Tatiana Martins; BARBOSA, Eliel Gomes; NASCIMENTO, Alessandra. Conflitos Organizacionais: os diversos tipos de conflitos interpessoais nas organizações suas causas e efeitos. Revista de Administração da UNIFATEA, v. 9, n. 09, 2015.

ASSIS, Marcelino Tadeu de. Indicadores de gestão de recursos humanos: usando indicadores demográficos, financeiros e de processos na gestão do capital humano. - Rio de Janeiro: Qualitymark Editora, 2014. 
BARBOSA, Analina de Lima. A arte de liderar: O PAPEL DO LÍDER NA GESTÃO DE CONFLITOS. IGARASSU, 2015.

BERGUE, Sandro Trescastro. Comportamento organizacional. Florianópolis: Departamento de Ciências da Administração/UFSC, 2010.

BISPO, Carlos Alberto Ferreira. Um novo modelo de pesquisa de clima organizacional. Production, v. 16, n. 2, p. 258-273, 2006.

CARVALHO, Karina M. Coqueiro. Uma análise do clima organizacional em uma empresa varejista de móveis e eletros na cidade de Picos - PI. 2010. 99p. Monografia (Graduação em Bacharelado em Administração) - Universidade Federal do Piauí, Picos, 2010. Picos-PI, 2010.

CONTE, Antônio Lázaro. Qualidade de vida no trabalho. Revista FAE business, v. 7, p. 32-34, 2003.

CHIAVENATO, Idalberto. Gestão de pessoas: o novo papel dos recursos humanos nas organizações. $14^{\text {a }}$ ed. Rio de Janeiro: Campus, 2008.

CRESWELL, John W. Projeto de pesquisa: métodos qualitativo, quantitativo e misto. 3. Ed. Porto Alegre: Artmed, 2010.

CROZATTI, Jaime. Modelo de gestão e cultura organizacional: conceitos e interações. Caderno de estudos, n. 18, p. 01-20, 1998.

DUARTE, Rosália. Pesquisa qualitativa: reflexões sobre o trabalho de campo. Cadernos de pesquisa, n. 115, p. 139-154, 2002.

DYNIEWICZ, Ana Maria. Avaliação da qualidade de vida de trabalhadores em empresa metalúrgica: um subsídio à prevenção de agravos à saúde. Fisioterapia em Movimento, v. 22, n. 3, 2017.

FRANÇA, Ana Cristina Limongi. Práticas de recursos humanos - PRH: conceitos, ferramentas e procedimentos. 1. ed. 11. Reimpr. São Paulo: Atlas, 2014.

GERHARDT, Tatiana Engel; SILVEIRA, Denise Tolfo. Métodos de pesquisa. Plageder, 2009.

GIL, Antônio Carlos. Métodos e técnicas de pesquisa social. 4. ed. São Paulo: Atlas, 1994. 
GÜNTHER, Hartmut. Como elaborar um questionário. Série: Planejamento de pesquisa nas ciências sociais, n. 01, 2003.

JUNIOR, John R. Schermerhorn; HUNT, James G.; OSBORN, Richard N. Fundamentos de comportamento organizacional. Porto Alegre: Bookman, 1999.

LACOMBE, Francisco Jose Masset. Recursos humanos: princípios e tendências. São Paulo: Saraiva, 2005.

LUZ, Ricardo. Gestão do Clima Organizacional. Rio de Janeiro: Qualitymark, 2006.

MARRAS, Jean Pierre. Administração de recursos humanos: do operacional ao estratégico. 15. ed. São Paulo: Saraiva, 2016.

NASCIMENTO, Eunice Maria; EL SAYED, Kassem Mohamed. Administração de conflitos: Gestão do capital humano, v. 5, p. 47-56, 2002.

OLIVEIRA, Daniele de; CARVALHO, Roberto José; ROSA, Adriano Carlos Moraes. Clima organizacional: fator de satisfação no trabalho e resultados eficazes na organização. Simpósio de Excelência em Gestão e Tecnologia, v. 9, p. 02, 2012.

ROBBINS, Stephen P. Comportamento organizacional. 11. ed. São Paulo: Pearson Prentice Hall, 2005.

ROBBINS, Stephen P. , JUDGE, Timothy A., SOBRAL Filipe. Comportamento Organizacional. 14. ed. São Paulo: Pearson Prentice Hall, 2010.

SIQUEIRA, Mirlene Maria Matias et al. Medidas do comportamento organizacional. 2002.

SOUZA, Carla Patricia da Silva. Cultura e clima organizacional: compreendendo a essência das organizações [livro eletrônico]. Curitiba: InterSaberes, 2014.

VECCHIO, Roberto P. Comportamento organizacional: conceitos básicos. - São Paulo: Cengage Learning, 2008.

WAGNER, John. Comportamento organizacional: criando vantagem competitiva. Editora Saraiva, 2017.

YIN, Robert K. Estudo de Caso: Planejamento e métodos. Bookman editora, 2015. 